\title{
Biological, physiological, immunological and nutritional assessment of farm-reared Litopenaeus stylirostris shrimp affected or unaffected by vibriosis
}

\author{
Chantal Mugnier ${ }^{a}$, Carole Justou $^{a}$, Hugues Lemonnier ${ }^{a, *}$, Jacques Patrois $^{a}$, Dominique Ansquer ${ }^{a}$, \\ Cyrille Goarant $^{\mathrm{b}}$, Jean-René Lecoz ${ }^{\mathrm{c}}$
}

\author{
${ }^{a}$ IFREMER-LEAD, BP2059, 98846 Nouméa Cedex, New Caledonia \\ ${ }^{b}$ Institut Pasteur de Nouvelle-Calédonie, Nouméa, New Caledonia \\ c IFREMER, UMR Physiologie et Ecophysiologie des Mollusques Marins, Technopole Brest-Iroise, BP70, 292800 \\ Plouzané, France
}

\author{
*: Corresponding author: Hugues Lemonnier, tel.: +6873525 71; fax: +687 287857 ; \\ email address: hlemonni@ifremer.fr
}

\begin{abstract}
:
Shrimp aquaculture in New Caledonia is subject to seasonal mortalities during grow-out due to highly virulent Vibrio nigripulchritudo $(\mathrm{Vn})$. To understand the mechanisms affecting shrimp resistance and leading to significant mortality, a shrimp ecophysiology and immunology survey was conducted on two farms, the first considered as a "control" farm (HC), the second affected by the disease (DF). Mortality observed during the survey at DF started 50 days after stocking and was typical of this disease. The main observations regarding shrimp were: (a) growth was not affected by the disease and was faster in the DF than in the HC pond; (b) disease did not affect one sex more than the other, or a specific part of the population in terms of weight; (c) the physical condition of shrimp did not specifically allow us to foresee disease outbreak; (d) shrimp at late premolt stage $D_{2}$ and early postmolt stage $A$ appeared to be at some points of the mortalities - but not continuously - the most sensitive to disease; (e) physiological, immunological and nutritional parameters of uninfected shrimp in the DF pond were altered, suggesting that environmental stress occurred just before the first mortalities; (f) data suggest that $\mathrm{Vn}$-infected shrimp are more stressed than the presumed healthy shrimp. Combined with pathological and environmental knowledge gained in parallel during this survey, a conceptual model is proposed. Results suggest that an unstable environment induced conditions (i) stressful for the shrimp, increasing their susceptibility to bacterial infections and (ii) favoring the proliferation of the pathogen in the pond. The combination of these two processes could lead to significant mortality.
\end{abstract}

\section{Highlights}

Shrimp health was surveyed on pond affected or unaffected by a vibriosis. Shrimp in molt stages A and D2 appeared to be the most sensitive. Even the health of uninfected shrimp was altered just before the first mortalities. Infected shrimp are more stressed than the presumed healthy shrimp. From our multidisciplinary approach, a conceptual model is proposed.

Keywords: Vibriosis ; Penaeid shrimp ; Field survey ; Physiology ; Immunology ; Nutritional status 
2 Aquaculture of the blue shrimp Litopenaeus stylirostris in New Caledonia is a developing

3 industry with an almost virus-free status. The domesticated species is tolerant of IHHNV, the

4 only significant virus present. However, the industry is affected by seasonal mortalities,

5 either during inter- and cold seasons ("Syndrome 93") (Mermoud et al., 1998, Goarant et al.,

6 2004a), or during the warm season ("Summer Syndrome") (Goarant et al., 2006a, Lemonnier

7 et al., 2006). These two pathologies reduce the profitability of the industry and are therefore

8 its main concerns. In both cases, mortalities are related to septicemic vibriosis due to Vibrio

9 penaeicida and Vibrio nigripulchritudo during grow-out (Goarant et al., 2006b). The origin

of these diseases cannot be explained by a single factor such as the presence of Vibrio.

11 Indeed, $V$. penaeicida can be found in the hemolymph of apparently healthy shrimp (Goarant

12 et al., 2004b) without mortality outbreaks, and V. nigripulchritudo can be detected in disease-

13 free ponds and shrimps (Goarant et al., 2006a). It is rather the combination of several factors

14 that account for disease, in particular, it is suspected, the interaction between the pond

15 ecosystem, the shrimp and the pathogen (Sniezsko, 1974; Lightner and Redman, 1998).

16 To understand the mechanisms affecting shrimp resistance and leading to significant

17 mortality, a multidisciplinary field survey linking pathology study (Goarant et al., 2006a),

18 pond ecosystem study (Lemonnier et al., 2010) andshrimp ecophysiology and immunology

19 (this study) was conducted on rearing ponds at two farms, one affected by Summer Syndrome

20 (designated farm DF for “diseased farm”), the other a healthy "control” farm (farm HC). The

21 aims of the pathology and the pond ecosystem studies were to follow and describe the

22 pathogen dynamics in shrimp and the ecosystem in both farms and to compare the

23 environmental conditions between the healthy and the diseased ponds. During this survey, no

24 mortalities linked to Summer Syndrome were recorded in HC pond. In DF pond, the first

25 mortalities were typically observed around d50, when the mean weight of shrimp was $5.9 \mathrm{~g}$. 
1 The results from the pathology study indicate that the shrimp larvae used were free of $V$.

2 nigripulchritudo at the time of stocking. Vibrio was detected for the first time in a shrimp

3 sampled 40 days after stocking in DF group. After that, the prevalence increased and

4 fluctuated between $16.7 \%$ and $93.3 \%$ until the end of the survey. Moribund/dead shrimp were

5 septicemic with $V$. nigripulchritudo. This Vibrio was also found in the sediment and the

6 water at some points of the survey. This bacteria cell was also observed in the HC pond, but

7 without mortality outbreak (Goarant et al., 2006a). The environmental study showed a higher

8 variability of phytoplankton in farm DF compared to farm HC. The beginning of the

9 mortality outbreak at DF followed an ecosystem shift characterized by a change in the phytoplankton community (Lemonnier et al., 2010). As part of this study, this paper presents

11 results on the biological, physiological and immunological parameter survey of shrimp.

12 Various relevant shrimp characteristics were studied throughout rearing, which was implemented simultaneously on diseased and healthy farms. Animals were examined for physical/health condition, including weight, growth, molt stages, hemolymph clotting time,

exoskeleton examination for necrotic lesions on the external body surface, gut emptiness and gross signs on body and appendages such as opaqueness of abdominal muscle, deformities, and colored gills and appendage segments. Most of those indicators are proposed by Fegan and Clifford (2001) for routine examinations for monitoring shrimp health on shrimp farms, and may be observed in shrimp affected by vibriosis (Lightner, 1988). Plasmatic physiological indicators of stress response - osmotic pressure (OP), total proteins (TP), oxyhaemocyanin $(\mathrm{OH})$, magnesium ions (Mg ions), glycemia, lactate - were selected in relation to results of previous studies carried out on L. stylirostris either under experimental conditions (Mugnier and Justou, 2004) or in field experiments (Lemonnier et al., 2004; Mugnier et al., 2006). Variation of OP was studied as a non-specific indicator commonly used for detecting physiological stresses, including L. stylirostris (Lignot et al., 2000). TP can 
1 serve as a significant source of metabolic energy for crustaceans (Claybrook, 1983). $\mathrm{OH}$ is

2 the main protein in the hemolymph and is applied in several functions such as oxygen

3 transport, enzymatic activities, osmoregulation and buffering (Paul and Pirow, 1997/98). The

$4 \mathrm{Mg}$ ions play an important role as a co-factor in enzyme systems and as a modulator of

5 hemocyanin in crustaceans (Morritt and Spicer, 1993). Variations of blood glucose levels

6 have been observed under several different environmental and physiological conditions (Hall

7 and VanHam, 1998). Lastly, lactate formation can be expected if higher energy production is

8 induced by environmental or physiological changes and anaerobic metabolism occurs. As

9 well as these physiological indicators, the total hemocyte count (THC) was measured as a 10 basic indicator of the immunological status of shrimp, since hemocytes are involved in most 11 of the immune mechanisms in crustacean (Johansson et al., 2000). Because the 12 hepatopancreas plays a key role in digestive processes, various indicators were also examined 13 in the hepatopancreas, such as the hepatosomatic index (HSI), glucose and TP concentrations, 14 and enzymatic activities such as trypsine. The aim was to gain insights into the dynamics of 15 hepatic energy reserves utilization in relation to mortality outbreak. The effect of the 16 presence of $V$. nigripulchritudo in shrimp hemolymph on physiological indicators was 17 analysed.

\section{Material and methods}

\subsection{Field survey procedure}

The survey was implemented from October 2002 (d32 after stocking) to January 2003 (d80) on Diseased and Healthy Farms. Two 3-ha earthen ponds, one in each farm, were stocked the same day with postlarvae (PL) originating from the same hatchery batch, at a density of 28 PL $\mathrm{m}^{-2}$ in farm DF and $35 \mathrm{PL} \mathrm{m}^{-2}$ in farm HC. Shrimp at both farms were fed the same commercial pellets throughout the survey. On each farm and thoughout rearing, daily pond 
1 mortalities were evaluated by counting dead and moribund shrimps at the pond edges. The

2 ponds were managed by the technical staff of each farm using to their standard techniques.

3 Shrimp were sampled alternately from rearing day 32, on even dates at farm DF and uneven

4 dates at farm HC. Sampling was carried out before the shrimp were fed in order to avoid any

5 variation in physiological parameters due to food intake (Lignot et al., 1999). One hundred

6 shrimp were caught quickly with a castnet in two different locations in the pond (50 in each

7 location, designed as representative of the pond by the farmers) and placed in aerated

8 seawater. Shrimp were individually weighed, their sex and molt stage determined, and the

9 body and exoskeleton examined for physical/health condition: necrotic or melanized lesions

10 (black spots) on the external body surface, colored gills, reddish appendage segments as a

11 result of chromatophore expansion, gut emptiness, deformity of exosqueleton or rostrum and

12 opaqueness of abdominal muscle were recorded. Moribund/dead shrimp were also sampled at

13 DF, in order to find out if shrimp affected by mortalities corresponded to a specific part of the

14 population in terms of weight, sex and molt stage.

15 Two molt stages were selected for the study of physiological and immunological states of

16 shrimp: the intermolt stage $\mathrm{C}$, which most studies on shrimps are concerned with, and the late

17 premolt stage D2. This second molt stage was selected because shrimps at premolt stage are

18 more sensitive to stress and less resistant to bacterial infection than intermolt animals (Le

19 Moullac et al., 1997; Mugnier and Justou, 2004). Of the 100 shrimp caught, the first 15 at

20 stage $\mathrm{C}$ and 15 at stage $\mathrm{D}_{2}$ were sampled for hemolymph and hepatopancreas analysis.

21 Hemolymph samples were collected rapidly from the ventral sinus using disposable syringes

22 and needles and were immediately (within 10-15 sec) distributed as follows. A 10- $\mu$ l

23 subsample of hemolymph was used for the measurement of OP with a Wescor osmometer. A

$24 \quad 10$ - $\mu$ l subsample of hemolymph was diluted in $390 \mu \mathrm{l}$ of distilled water and $\mathrm{OH}$ absorbance

25 was measured at $335 \mathrm{~nm}$ (characteristic of $\mathrm{OH}$ ). The $\mathrm{OH}$ concentration was calculated using 
1 an extinction coefficient $\left(\mathrm{E}^{\mathrm{mM}}{ }_{1 \mathrm{~cm}}\right)$ of 17.26 (Chen and Cheng, 1993). A subsample of

2 hemolymph was mixed with $10 \%$ sodium citrate as anti-coagulant ( 9 volumes hemolymph

3 for 1 volume citrate) and centrifuged $5 \mathrm{~min}$ at $800 \mathrm{~g}, 5^{\circ} \mathrm{C}$. The supernatant (plasma) was

4 stored at $-80^{\circ} \mathrm{C}$ for further biochemical analysis. A $10-\mu \mathrm{l}$ subsample was diluted in $30 \mu \mathrm{l}$ of

5 Alsever with $10 \%$ formalin for counting the THC from day 50 only, when mortalities started

6 in DF pond. The number of hemolymph samples which coagulated within 10 seconds was

7 recorded. Sampled shrimps were dissected and the hepatopancreas was carefully removed

8 and weighed. HSI was calculated individually as the ratio between wet hepatopancreas

9 weight and total wet body weight. The hepatopancreases were immediately frozen in liquid

10 nitrogen and back in the laboratory were stored at $-80^{\circ} \mathrm{C}$ until analysis. Dead and weak

11 shrimp were collected twice daily along the pond edges, either by farm staff or scientists

12 Weight, physical condition, sex and molt stage were also recorded on fresh dead shrimp and

13 weak shrimp. The analyses of $V$. nigripulchritudo presence in the hemolymph of apparently

14 healthy shrimp allowed us to differentiate the presumed healthy (Vn- shrimp) from the

15 infected (Vn+ shrimp) (Goarant et al., 2006a).

\section{$17 \quad 2.2$. Molt stage determination}

Six molt stages were defined according to the retraction of the epithelium within setae of the antennal scale (Drach, 1939; Chan et al., 1988). Shrimps were classified as A and B for the early and late postmolt stages respectively, $C$ for intermolt and $D_{0}, D_{1}, D_{2}$ for premolt stages. $D_{0}$ was the very early premolt stage, when the epidermis starts to retract. $D_{2}$ was the late premolt stage prior to ecdysis, when the epidermis is at maximal retraction and it is possible to distinguish the developing seta.

\subsection{Plasma constituent analysis}


1 A 25- $\mu$ l subsample of plasma was mixed with $50 \mu$ ice-cold $6 \%$ perchloric acid and centrifuged for 15 min at $13000 \mathrm{~g}$ for deproteinisation. $\mathrm{pH}$ of supernatant was neutralized with $14 \mu \mathrm{l}$ of $\mathrm{KOH} 3 \mathrm{M}$ (Paterson, pers. com.). Commercial kits formerly adapted to a microplate were used to determine glucose (Sigma) (Glycemia), lactate and Mg ions (Biomérieux). Absorbance was read on a microplate reader (Digiscan Asys Hitech 340) and concentrations were calculated from a standard curve of known substrates. Glucose and lactate were assayed on deproteneized plasma. Plasma level of TP was measured by the method described by Lowry et al. (1951) adapted to microplate technique, using bovine serum albumin (Sigma, molecular weight: 66,000 daltons) as a standard.

\subsection{Total hemocyte count (THC)}

Numeration of hemocytes was carried out within $72 \mathrm{~h}$ following sampling, using an inverted phase contrast microscope (Leica).

\subsection{Hepatopancreas analysis}

Glucose, TP and trypsine activity were assayed on hepatopancreas extracts. Hepatopancreas was weighed with a microbalance and cut into small pieces, which were homogenized either in chilled (1:10 w:v) distilled water for glucose and total proteins assay or in chilled Naphosphate buffer $10 \mathrm{mM}$ at a final concentration of $100 \mathrm{mg} / \mathrm{ml}$, then centrifuged at $20000 \mathrm{x} \mathrm{g}$ for $20 \mathrm{~min}$ at $4^{\circ} \mathrm{C}$ for trypsine assay. Samples were analysed individually. For TP assay, proteins were extracted with $\mathrm{NaOH} 2 \mathrm{~N}$. TP was measured by the Lowry and al. (1951) technique adapted to the microplate method, using bovine serum albumin (Sigma, molecular weight: 66,000 daltons) as a standard. Glucose was assayed with the Dubois method. For trypsine activity, supernatant was dissolved at 1:5 v/v in chilled TRIS buffer $\mathrm{pH}$ 8. Trypsine activity was evaluated by the rate of hydrolysis of N-Benzoyl-l-Arginine-p-nitroanilide 
1 (BAPNA) (SIGMA) as a synthetic substrate. BAPNA (1 mM) was dissolved in $1 \mathrm{ml}$ of

2 dimethylsulfoxide (DMSO) and made up to $100 \mathrm{ml}$ with Tris buffer, $\mathrm{pH} 8$ containing $20 \mathrm{mM}$

$3 \mathrm{CaCl}_{2}$. Assay was adapted from Erlanger et al. (1961) to a microplate. Hepatopancreas

4 extracts $(25 \mu \mathrm{l})$ were added to $225 \mu \mathrm{l}$ of substrate solution at $25^{\circ} \mathrm{C}$ and changes of absorbance

5 at $405 \mathrm{~nm}$ (microplate reader, Digiscan Asys Hitech 340) were recorded over a 10 min period

6 (50 measures per min). Trypsin activity units were expressed as the change in absorbance

$7 \mathrm{~min}^{-1} \mathrm{mg}^{-1}$ of protein of the enzyme used in the assay ( $\triangle \mathrm{Abs} \mathrm{min}^{-1} \mathrm{mg}^{-1} \mathrm{prot}^{-1}$ ).

8

\section{$9 \quad$ 2.6. Data and statistical analysis}

Biological parameters

Weight data from the field survey were log transformed and the slopes of the linear regression obtained for each farm were compared using Student's t-test. Comparisons of weight of apparently healthy shrimp between farms, and within farm DF between apparently healthy shrimp and dead/moribund shrimp, were carried out with ANOVA at 5\% significance threshold (Statview Computer Software). Differences in mortality between shrimp at different molt stages, and comparisons between apparently healthy shrimp and moribund/dead shrimp for sex and molt stage, were analysed by Chi-square tests $(<\mathrm{chi}>2)$ at $5 \%$ significance threshold.

\section{Physiological and immunological aspects}

Samplings were grouped in 4-day periods so as to have similar periods comparable between farms. Comparison for each rearing period was then carried out with ANOVA at the 5\% significance threshold (Statview Computer Software). Data were expressed and plotted as mean \pm standard error. Comparison between farms was carried out on Vn- shrimp by ANCOVA (statgraph 5.1 software) with farm and molt stages as factors and shrimp weight as 
1 cofactor. In DF, comparison was carried out between $\mathrm{Vn}+$ and $\mathrm{Vn}$ - shrimp with Vibrio and

2 molt stage as factors and shrimp weight as cofactor. Correlations between hemolymph and

3 hepatopancreas parameters were analysed (Statview Computer Software).

$5 \quad$ 3. Results

$6 \quad$ 3.1. Mortality and final survival

7 No mortality related to V. nigripulchritudo was observed at HC. However, some mortality 8 occurred between d45 and d49 (Fig. 1A). Hydromedusae Clytia sp. (Le Borgne pers. com.) at

9 high concentration (between 15 and 20 individuals $\mathrm{L}^{-1}$ ) in pond water were noticed for the 10 first time at $\mathrm{d} 41$ at this farm. After $\mathrm{d} 49,0$ to 3 hydromedusae $\mathrm{L}^{-1}$ were counted. Mortality in 11 the pond stopped when the concentration decreased to fewer than 5 individuals $\mathrm{L}^{-1}$. Despite 12 this mortality, the final survival was $62 \%$, as generally observed on this farm. In DF pond, 13 the first dead shrimp were observed around d50 (Fig. 1B), when shrimp sampled in the pond 14 had an average weight of $5.9 \pm 0.1 \mathrm{~g}$. Two main periods of mortality were observed: one 15 between $\mathrm{d} 54$ and $\mathrm{d} 64$ and the other peaking at d77. An intermediate period was observed between d65 and d71. Final survival at harvest was 27\%.

\subsection{Weight}

19 Weight equations of the power regression were (weight) $=0.017(\text { day })^{\wedge} 1.498$ for $\mathrm{HC}\left(\mathrm{r}^{2}=\right.$ $0.97)$ and (weight) $=0.004(\text { day })^{\wedge} 1.887$ for DF $\left(r^{2}=0.99\right)$. The curves crossed at $d 54$ for an 21 average weight of $6.9 \mathrm{~g}$ (Fig. 2). The slope obtained with the linear regression was significantly higher at DF than in the HC group $(p<0.001)$. Before $\mathrm{d} 54$, daily average weight of shrimp from HC was higher than in the DF group, and conversely after d54. Weight of moribund and dead shrimp was not significantly different from the weight of apparently 
1 healthy shrimp throughout the survey, except on days 56, 66, 70, and 76, when dead shrimp

2 weighed less than apparently healthy shrimp (ANOVA, $p<0.05$ ).

3

4

\section{$3.3 \underline{\text { Sex }}$}

There were $47.2 \%$ males in the HC group and $49.7 \%$ in the DF group, with no difference in sex distribution in the population $(<\mathrm{chi}>2, p=0.106)$ at either farm. No difference in weight gain could be observed between males and females at either farm. Summer syndrome mortality affected both females $(n=344)$ and males $(n=307)(<$ chi $>2, p>0.05)$ in the DF group.

\subsection{Molt stages}

The mean percentages of each molt stage observed during the survey are reported in Table 1. There were no significant differences between farms for each stage (ANOVA, $p>0.20$ ). Nor were there any differences found when looking separately at the period before mortality (d3249) and the period during mortality (d50-80). The molt stage could be identified in $89.3 \%$ of the dead/moribund shrimp (658 animals) at DF. The percentage of shrimp at stages $A$ and $\mathrm{D}_{2}$ was significantly higher in moribund/dead than apparently healthy shrimp ( $<$ chi $>2, p<0.05$ ) (Table 2). Conversely, there were fewer moribund/dead shrimp at stage $D_{1}$ than in the sampled population, and no difference for stages $B, C$ and $D_{0}$ (Table 2). Moribund/dead shrimp at stage A were observed between d54 (30\%) and d60, and on d70 (13\%), d74 (4.4\%) and $\mathrm{d} 76$ (7.9\%), roughly corresponding to the beginning of peak mortalities, while at the same time a maximum of $2 \%$ of the population was at stage A (Fig. 1B). The difference between moribund/dead and healthy shrimp at stage $\mathrm{D}_{2}$ was particularly noticeable at the beginning of mortality at days 54, 56 and 58 with respectively 30\%, 58\% and 36\% of moribund/dead shrimp at late premolt stage, as against $12 \%, 25 \%$ and $24 \%$ in the apparently healthy shrimp (<chi $>2, p<0.05$ ). This significant difference was also observed at days 68 
1 and 70 with $50 \%$ and $51 \%$ of the dead/moribund shrimp at stage $\mathrm{D}_{2}$ as against $24 \%$ and $11 \%$

2 in the sampled population.

\subsection{Physical/health conditions}

Shrimp with deformities represented less than $0.5 \%$ of the sampled population in both farms

(Table 3). The number of shrimp with an empty gut was significantly higher in HC than in

DF group (Table 3). Peaks of animals with empty gut were observed around d43-47, 55, 61-

65 and $\mathrm{d} 75$ in the HC group. This number remained low throughout the survey in the DF group, but tended to increase from d70 onwards. All moribund/dead shrimp had an empty gut. The percentage of shrimp with necrotic lesions on the external body surface was less than $1.7 \%$ of the sampled shrimp in both farms (Table 3). Animals with orange-colored gills were three times more frequent in the DF group compared to HC (Table 3). Necrotic lesions were observed only at the end of the survey, after $\mathrm{d} 70$ for both farms. HC had twice the percentage of shrimp with red-colored appendage segments compared to the DF group (Table 3). Most of the shrimp with colored appendage segments in HC group were observed during the medusa bloom, and especially after $\mathrm{d} 65$. In general, shrimp at stage $\mathrm{D}_{2}$ were more likely to have red-colored appendage segments ( $<$ chi $>2, p<0.05$ ), except during the period d47-49 of rearing, when all molt stages were equally affected. The overall number of shrimp with opaqueness of abdominal muscle was twice as high in HC than in the DF group (Table 3). They were observed at several periods in the HC group, but the highest peak was between d53 and d55, with more than $60 \%$ of the sampled animals being affected. A smaller peak was also observed in the DF group between $\mathrm{d} 46$ and $\mathrm{d} 48$. Only $4.8 \%$ of the moribund shrimp had an opaque abdominal muscle in the DF group, a percentage significantly lower than that observed in apparently healthy shrimp ( $<$ chi $>2, p=0.0002)$. All molt stages could similarly be affected by opaqueness of abdominal muscle. 
2 3.6. Physiological and immunological parameters

3 The mean percentage of animals with hemolymph that coagulated within 10 seconds was

4 significantly higher in DF than in the HC group (11.1\% against $4.6 \%,<$ chi $>2, p<0.0001)$.

5 At HC, the highest percentages were observed between d39 and d51, with a peak (20\% of the

6 animals sampled) at d45 (during the medusa bloom). At DF, mean peaks were observed at 7 d52-54, d64 and d74-76 with 48\%, 38\% and 30\% respectively of the sampled animals 8 affected.

The kinetics of physiological parameters of Vn-free shrimp at stages $C$ or $D_{2}$ is presented on

Fig. 3. Results from ANCOVA (Table 4) showed that all hemolymph parameters studied were significantly different between farms, except OP $(p=0.06)$ : Mean glycemia, $\mathrm{Mg}$ ions, $\mathrm{OH}$, TP and THC were higher in shrimp from farm HC than from DF, while lactate was lower. At the beginning of the survey (d32-40) and comparatively to DF, HC was characterized by shrimp with a concentration of Mg ions 2.7 times higher (Fig. 3C) and a glycemia 1.9 times lower (Fig. 3E). A positive peak in OP (Fig. 3A) and negative peaks in TP (Fig. 3B) and $\mathrm{OH}$ (Fig. 3F) were also observed during the period d37-40. Between d41 and d48 parameters developed in a similar way for both farms and no significant differences were found whatever the parameter studied. During the following period (d49-d56), characterized by the beginning of the mortality at DF, glycemia and TP were lower in shrimp from farm DF than from farm HC, while OP tended to be higher in HC than in the DF group. Glycemia remained significantly lower in the DF group until d76, except during the period d61-d68. The lack of significance for this period may be explained by the low number of Vn-free shrimp in the sample jeopardizing the statistical power of our analysis ( $n=5)$, as $80 \%$ of shrimp were carrying Vn (Vn+) (Goarant et al., 2006a). During the last period of the survey 
1 (d71-80), a significant increase was observed in the HC goup, but also in the DF group, while

2 between d69-72 the concentration was close to the basal level (d32-40) observed during the

3 first part of the survey at DF.

4 In the period d61-68, farm DF presented a lower OH than farm HC (Fig. 3F), as opposed to

5 higher lactate concentrations (Fig. 3D). Lack of data between d65-68 due to insufficient

6 intermolt Vn- shrimp prevented us from properly comparing THC (Fig. 3G), but it was

7 significantly higher at HC than in the DF group from d69 to d72.

8

$9 \quad$ 3.7. Hepatopancreas analysis

Table 4 shows statistical results from ANCOVA, with a significant farm effect on HSI, TP

11 and trypsine activity. At the beginning of the survey, HSI was lower in the HC group 12 comparatively to DF (Fig. 4A). From d53 onwards, this index was similar at both farms. 13 From d45 to d48, TP was particularly high at DF (168.3 $\left.\pm 14.8 \mathrm{mg} \cdot \mathrm{ml}^{-1}\right)$. From d49 it 14 dropped sharply and remained up to $25 \%$ lower than the concentration observed in the HC 15 group until the end of the survey (Fig. 4B). Glucose concentrations were not significantly 16 different between ponds (Table 4, Fig. 4C). Trypsine activity was significantly lower at HC 17 compared to the DF group (Table 4), though from d41 on, the patterns were similar in both 18 ponds (Fig. 4D).

\subsection{Presence of $V$. nigripulchritudo in shrimp hemolymph}

21 At DF, Vn+ shrimp were observed from d40 onwards in the population sampled (Goarant et 22 al., 2006a). Within the $\mathrm{Vn}+$ shrimp population, the percentage of premolt shrimp was significantly higher than that of intermolt shrimp (80.4\% against 49.4\%) $(<\mathrm{chi}>2, p=0.0005)$ when mortality appeared (d51-60). Subsequently the difference was no longer significant. Analysis of indicators of physical condition did not show any significant difference between 
$1 \quad \mathrm{Vn}+$ and Vn-. The percentage of shrimp with reduced clotting time was significantly lower in

$2 \mathrm{Vn}+$ shrimp compared to $\mathrm{Vn}$ - shrimp (respectively $10.2 \%$ as against $16.7 \%$; $<$ chi $>2, p<$

3 0.05). Glycemia, $\mathrm{OH}, \mathrm{TP}$ and THC were significantly lower, and $\mathrm{OP}$ and $\mathrm{Mg}$ ions were

4 significantly higher in $\mathrm{Vn}+$ shrimp than Vn- shrimp (Table 5). The differences for the

5 parameters analysed in the hepatopancreas between $\mathrm{Vn}+$ and $\mathrm{Vn}$ - shrimp were not significant

6 (Table 5).

7

\section{Discussion}

9 Physical/health conditions were not characteristics of shrimp sampled in the DF pond before 10 and during mortality. As for many types of disease (e.g. yellowhead virus), these overall 11 signs are not sufficiently specific to detect an outbreak of Summer Syndrome and to help us understand the mechanisms affecting shrimp resistance, especially since some of them, such as empty gut and opaqueness of abdominal muscle, were mostly observed at HC without any 14 link with mortality.

15 Peaks of shrimp with a reduced hemolymph clotting time were observed during mortalities linked to vibriosis or when hydromedusae were present. This reduced clotting time could be the result of an immunostimulatory effect rather than a disease symptom, as clotting time is usually delayed in diseased shrimp (Lightner, 1988; Fegan and Clifford, 2001, Song et al., 2003). It could also be a short-term response to external stressful conditions, as observed for some crustaceans (Jussila et al., 2001).

Results showed that growth was not affected by the disease and was faster at DF than in the HC group. In a previous study on Summer Syndrome, a possible negative effect of fast growth on the resistance of shrimp to infection and/or environmental stress was suspected 24 (Lemonnier et al., 2006). This effect has already been demonstrated for the cladoceran 25 Daphnia magna (Barber et al., 1994; Smolders et al., 2005). A higher growth rate implies an 
1 increase in the molting frequency (Gauquelin et al., 2007), and high molting frequency might

2 not only increase energy expenditure for exuviations, but also alter the animal's entire energy

3 allocation strategy (Cockcroft and Wooldridge, 1985). Extra energy allocated to growth and

4 molting may be derived from other functions involved in reactions and/or adaptation to

5 environmental variations, including response to pathogens. However, as the growth rate was

6 also relatively high in the HC group, it cannot be assumed that it is a causative factor on its

7 own, but could be one promoting factor among others.

8

9 In our study, moribund and dead shrimp were observed during periods corresponding to peak molting, as previously reported by Fegan and Clifford (2001) in ponds infected with WSSV.

11 Stages $\mathrm{D}_{2}$ and $\mathrm{A}$ were the molt stages the most affected by mortality at the beginning of peak 12 mortalities, while premolt stage $\mathrm{D}_{1}$ was the least affected. Interestingly, shrimp at postmolt stage B were not particularly sensitive, as the percentage observed in moribund/dead shrimp was exactly the same as that observed in the sample population. Le Moullac et al. (1997) have shown that $L$. stylirostris challenged at premolt stage D are more sensitive to a Vibrio infection than animals at intermolt stage C. Experimental infection of the white shrimp $L$. vannamei with a pathogenic strain of Vibrio alginolyticus showed that shrimp at postmolt stage $(A+B)$ were more sensitive to infection than shrimp at premolt stage $\left(D_{0}\right.$ to $\left.D_{3}\right)($ Liu et al., 2004). Similarly, preliminary experimental work in L. stylirsotris infected with $V$. nigripulchritudo gave the same result (De Decker and Goarant, pers. com.). On the other 21 hand, late premolt and postmolt shrimp L. stylirostris are more sensitive to stressful 22 conditions such as severe hypoxia than intermolt animals (Mugnier and Soyez, 2005) and the combination of two stressful conditions such as ammonia and hypoxia can lead to mortality affecting more than $50 \%$ of the shrimp at late premolt stage and none of the other stages (Mugnier et al., 2008). It is too early to conclude that there is a predominant effect of 
environmental conditions rather than Vibrio infection on shrimp mortality affecting one molt

2 stage rather than another, but this hypothesis needs to be tested.

4 In the DF group, decreasing glycemia observed in Vn-free shrimp appeared just before the

5 first dead shrimp were observed. Hypoglycemia is a long-term stress indicator, as observed in

6 Nephrops norvegicus submitted to hypoxia for 3 weeks (Hagerman et al., 1990). The data

7 suggest an increase of carbohydrate catabolism and turnover, as indicated by hypoglycemia

8 (Fig. 3E), and concomitantly the production of lactate (Fig. 3D) as the end-product of

9 glycolysis. Lactate is produced by muscular work (functional anaerobiosis) and excess of

10 lactate is transferred from the muscle to the hemolymph. However, Racotta and Hernandez-

11 herrara (2000) suggested a reduced use of carbohydrate through anaerobic metabolism when

12 animals are exposed to stress. Furthermore, decrease of both TP (Fig. 3B) and OH (Fig. 3F)

13 is probably the result of proteolysis to satisfy increased metabolic demand caused by a

14 stressor situation involving reduced availability of energy. Under experimental conditions, it

15 was also demonstrated for several shrimp species including L. stylirostris that TP and OH

16 decrease under environmental stress (e.g. Chen and Cheng, 1995; Mugnier and Justou, 2004).

17 The increase in oxygen demand along with the increase in metabolic demand represents a 18 conflicting situation for the animals, because more oxygen is needed at the tissue level. It

19 would be reasonable to suggest that energy obtained from anaerobic metabolism could 20 partially compensate for this problem. Stress therefore has a considerable and rapid effect on 21 respiratory function. Wabete et al. (2008) demonstrated that L. stylirostris is characterized by 22 a low arterial hemolymph pressure and at $28^{\circ} \mathrm{C}$ by a very high $\mathrm{O}_{2}$-demand to ensure high 23 cellular $\mathrm{O}_{2}$ requirements and $\mathrm{O}_{2}$ consumption. During stressful events, a mismatch between $24 \mathrm{O}_{2}$-demand and $\mathrm{O}_{2}$-supply could contribute to the increase in the anaerobic metabolism of the 25 shrimp observed in our survey through impairment of their hemolymph $\mathrm{O}_{2}$-carrying capacity. 
2 The difference in studied physiological parameters between $\mathrm{Vn}+$ and $\mathrm{Vn}$ - shrimp

3 (hypoglycemia, lower $\mathrm{OH}$, TP and THC and higher PO and Mg ions in Vn+ shrimp) suggest

4 that $\mathrm{Vn}+$ shrimp are more stressed than Vn- shrimp. The effect of pathogen on crustacean

5 physiology has already been observed. Increase in Mg ions is a stress indicator as observed in

$6 \quad$ P. monodon and L. stylirostris (Boglio, 1995; Boglio and Goarant, 1996), but also an

7 indicator of infection as observed in M. japonicus infected with a virus (Hennig et al., 1998).

8 Moreover, experimental infections with white spot syndrome virus (WSSV) in P. indicus

9 showed pathogen effects on variations in physiological and immunological parameters, such

10 as hyperglycemia, decrease in $\mathrm{OH}$ and THC, and increase in PT (Yoganandhan et al., 2003).

11 Similarly in L. vannamei infected with Taura virus, decreases of PT, OH and THC were

12 observed (Song et al., 2003). Hyperglycemia and increase in lactate were also observed in $L$.

13 vannamei challenged with $V$. alginolyticus (Hsieh et al., 2008). A sublethal infection with

14 Vibrio led to a negative effect on THC in L. stylirostris (Goarant and Boglio, 2000) as well as

15 a decrease in antioxidant defences (Castex et al., 2009). Several factors can cause a reduction

16 of hemocyte numbers, such as hemocyte infiltration in infected tissues, low cell replacement

17 by hematopoietic organs and hemocyte death through apoptosis. Immune assessment

18 conducted in farm-reared L. vannamei infected by IMNV virus showed that the immune

19 system of shrimp responds only at a late stage of the disease (Costa et al., 2009).

21 Environmental factors may also have an effect on immunological response (Le Moullac and 22 Haffner, 2000), including on THC and on susceptibility to Vibrio (Le Moullac et al., 1998;

23 Liu et al., 2004; Cheng et al., 2007). THC values during d49-60 (between $0.8410^{7} \pm 0.1310^{7}$

24 and $1.3510^{7} \pm 0.1210^{7}$ hemocytes/ml hemolymph) is low compared to mean values

25 observed in L. stylirostris in New Caledonia (3.2 $10^{7}$ hemocytes/ml hemolymph, Goarant, 
1 pers. Com.). As data before d49 are lacking, it is not possible to say whether this was a

2 transitory value. THC in Vn- shrimp located in ponds affected by the disease remains lower

3 than usual till the end of the survey, suggesting a potential effect of the environment.

4 Attention needs to be paid in future to observing the immunological responses (Bachère,

5 2000). Different cell types (hyaline, semi-granular and granular) and antimicrobial peptides

6 could be monitored to analyze more precisely the immunological responses of shrimp to

7 vibriosis in pond aquaculture (Le Moullac and Haffner, 2000; Rolland et al., 2010).

8

9 The hepatopancreas is considered to be the main storage organ in shrimp and HSI is used to follow the general nutritional status of crustaceans. Data from our survey were in the range of 11 values found by Castex et al. (2008) for 9-10 g L. stylirostris (0.045 - 0.048), but higher than 12 those reported for L. vannamei by Sánchez-Paz et al. (2007). At the beginning of the survey, HSI was about $20 \%$ higher in the DF group compared to HC, suggesting better digestion and adsorption of food, which in turn contribute to improving hepatic storage in the digestive gland. Moreover the number of shrimp with an empty gut in the morning before feeding was significantly higher in HC than in the DF group. On the basis of these results, it cannot be assumed that shrimp feeding is a disease causative factor. However, from a few days before the beginning of mortalities linked to Summer Syndrome up until the end of the survey, total protein concentrations in hepatopancreas were lower in the DF group than in HC (25\% lower at the end of the survey), indicating a decrease in protein storage. It is generally accepted that protein is the main energy source in crustaceans. No difference between $\mathrm{Vn}+$ and $\mathrm{Vn}$ - shrimp could be shown, suggesting that the presence of the pathogen in hemolymph cannot by itself account for this result.

Trypsin is considered to be the most important enzyme in digestive dietary protein, and together with chymotrypsin is the most abundant proteolityc enzyme in the digestive gland of 
1 crustaceans. Trypsin activity (TA) is modulated by several internal and external factors such

2 as genetic factors, frequency of feeding, origin and quantity of dietary protein, molting and

3 stress (see the review by Sainz Hernández and Córdova Murueta, 2009). Results on TA in the

4 digestive gland showed that enzyme activity was significantly higher in the DF group

5 compared to HC. Apart from a stress factor, the others factors involved in the TA were

6 similar. One hypothesis is that the difference between ponds could be due to a stress effect as

7 observed by Córdova Murueta et al. (2004) in experimental conditions.

8 Shrimp have a limited but effective lipid and CHO metabolism that is used according to

9 specific energetic and/or physiological and/or structural demands (Charmantier et al., 1994).

10 For example, under short-term starvation, a rapid decrease of plasma and hepatopancreas

11 glucose is detected (Sánchez-Paz et al., 2007). Results from our survey show no difference

12 between the two ponds, suggesting that animals were able to regulate the glucose 13 concentration in the digestive gland whatever the pathological or/and environmental 14 conditions.

The differential evolution of physiological and immunological parameters of pathogen-free 17 shrimp in DF group from d49 tends to indicate that shrimp were affected by the environmental conditions. During mortality outbreaks, pond DF water column parameters did not generally present values independently considered to be stressful as defined in experimental conditions, but rather high variability and unstable values, such as for dissolved oxygen (Lemonnier et al., 2006; Lemonnier et al., 2010). Variations were fast, setting in a 22 few days (or even in a few hours) and it is difficult to describe precisely the dynamic especially as many phenomena were occurring at the same time.

24 Although they live in water, shrimps are also in contact with the pond bottom and sediment. pH values in farm DF sediment were close to stressful values: $80 \%$ of values were below 6.6 
1 (Lemonnier et al., 2010), the upper limit below which osmoregulation in L. stylirostris is

2 affected (Lemonnier et al., 2004). However, similar values of $\mathrm{pH}$ were observed in sediment

3 at farm HC from d50 without any physiological response being detected. But experimental

4 studies where one parameter such as ammonia, hypoxia or nitrites is studied in controlled

5 conditions do not reflect the complexity of the pond environment and the fact that the impact

6 of stress increases in a synergic rather than a cumulative fashion. For instance, it has been

7 shown that low dissolved-oxygen levels increase the toxicity of ammonia to the shrimp $L$.

8 stylirostris (Mugnier et al., 2008). Unfortunately, few studies have been conducted so far on

9 the effects of combined environmental conditions. A cumulative effect of these

10 environmental conditions may have decreased the resistance of shrimps to the disease.

11 Another hypothesis is that an unknown environmental factor or factors not examined in this

12 study are involved.

14 A conceptual model

15 Figure 5 presents a model of the disease conceptualized from the literature (Sniezsko, 1974;

16 Lightner and Redman, 1998) and all the results from this survey (Goarant et al., 2006;

17 Lemonnier et al., 2010; this study). In this model, we postulate that mortalities occur in an

18 unstable environment, characterized by sudden phytoplanktonic changes and abiotic

19 parameters (pH, ammonia, etc.) close to stressful values. Such conditions, which may occur

20 in combination with an other unknown triggering factor, weaken the host physiological

21 status, as suggested by the results of our comparative study between the two farms and the

22 evolution of physiological parameters, increasing shrimp susceptibility to bacterial infections

23 (Fig. 5, arrow 1). A potentially negative effect of excessively fast growth on shrimp

24 resistance to infection and/or environmental stress is suspected and will be addressed by

25 further investigations. The molt stage could also play a role in disease outbreak (Fig. 5, arrow 
1 2). While the occurrence of pathogenic Vibrio isolates in the pond does not necessarily lead

2 to mortality outbreaks, it has been previously reported that the colonization of the pond

3 ecosystem by the pathogen occurs at the onset of the disease (Goarant et al., 2007). The

4 presence of the pathogen in pond sediment before mortalities suggests that sediment could be

5 a potential infecting reservoir (Walling et al., 2010). It has also been shown that $V$.

6 nigripulchritudo is able to survive in sediment throughout an 18-week drying period and

7 therefore from one rearing cycle to the next (Labreuche, pers. com.). However, further

8 studies are needed to determine the environmental factors controlling pathogen proliferation

9 and virulence in ponds (Fig. 5, arrow 3). Our results suggest that Vn-infected shrimp are

10 more stressed than presumed healthy shrimp. However, the data do not allow us to definitely

11 conclude whether the physiological and immunological responses observed in Vn-infected

12 shrimp result either from the presence of the pathogen in shrimp hemolymph or from a

13 different shrimp susceptibility (Fig. 5, arrows 4). Our results suggest that an unstable

14 environment could be the key factor explaining the presence of stressed shrimp and the

15 proliferation of the highly virulent pathogen in ponds. The combination of these two

16 conditions may induce mortality outbreaks.

17

18

19

\section{Aknowledgements}

This work was supported by research grants from the North and South Provinces of New Caledonia. The authors would like to thank the owners of the private farms and their employees for giving us access to the farm facilities and the shrimp, and enabling this experiment to be conducted in good conditions. We also want to thank A. Herbland for overall scientific supervision of the DESANS program, as well as P. Brun, D. Coatanea, L. Della Patrona, E. Goyard, Y. Harache, J. Herlin, F. Imbert, C. Lambert, A. Legrand, P. Lemaire, A.L. Marteau, J.M. Peignon, E. Pita, L. Salery, B. Soulard of the Department of 
1 Aquaculture in New Caledonia, who kindly helped in the sampling and analysis, and the

technical staff for the installation of temporary laboratories.

\section{References}

Bachère, E., 2000. Shrimp immunity and disease control. Aquaculture 191, 3-11.

Barber, I., Baird, D., Calow, P., 1994. Effect of cadmium and ration level on oxygen consumption, RNA concentration and RNA-DNA ratio in two clones of Daphnia magna Straus. Aquat. Toxic. 30, 249-258.

Boglio, E., 1995. Measurement of stress in broodstock leader prawns (Penaeus monodon) following capture by trawling and transport to hatcheries. PhD dissertation, University of Queensland, Queensland. 155 pp.

Boglio, E., Goarant C., 1996. Hemolymph magnesium as a measure of acute physiological stress in wild broodstock Penaeus monodon and cultured broodstock P. stylirostris. In: SEAFDEC (Ed.), Second international conference on the culture of Penaeid prawns and shrimps, 14-17 May 1996, Iloilo city, Philippines, p. 101.

Castex, M., Chim, L., Pham, D., Lemaire, P., Wabete, N., Nicolas, J.-L., Schmidely, P., Mariojouls, C., 2008. Probiotic P. acidilactici application in shrimp Litopenaeus stylirostris culture subject to vibriosis in New Caledonia. Aquaculture 275, 182-193.

Castex, M., Lemaire, P., Wabete, N., Chim, L., 2009. Effect of probiotic Pediococcus acidilactici on antioxidant defences and oxidative stress of Litopenaeus stylirostris under Vibrio nigripulchritudo challenge. Fish Shellfish Immunol., 28: 622-631.

Chan, S.-M., Rankin, S. M., Keeley, L. L., 1988. Characterization of the molt stages in Penaeus vannamei: setogenesis and hemolymph levels of total protein, ecdysteroids, and glucose. Biol. Bull., 175, 185-192.

Charmantier, G., Soyez, C, Aquacop, 1994. Effect of moult stage and hypoxia on osmoregulatory capacity in the peneid shrimp Penaeus vannamei. J. Exp. Mar. Biol. Ecol. 178, 223-246.

Chen, J.-C., Cheng, S.-Y., 1993. Studies on haemocyanin and hemolymph protein levels of Penaeus japonicus based on sex, size and moulting cycle. Comp. Biochem. Physiol. 106B(2), 293-296.

Chen, J.-C., Cheng, S.-Y., 1995. Hemolymph oxygen content, oxyhemocyanin, protein levels and ammonia excretion in the shrimp Penaeus monodon exposed to ambient nitrite. J. Comp. Physiol. 164B (7), 530-535.

Cheng, S.-Y., Hsu, S.-W., Chen, J.-C., 2007. Effect of sulfide on the immune response and susceptibility to Vibrio alginolyticus in the kuruma shrimp Marsupenaeus japonicus. Fish Shellfish Immunol. 22, 16-26.

Claybrook, D.L., 1983. Nitrogen metabolism. In: Mantel, L.H. (Ed.), The Biology of Crustacea. Internal Anatomy and Physiological Regulation, vol. 5. Academic Press, New York, pp. 162- 213. 
Cockcroft, A.C., Wooldridge, T., 1985. The effects of mass, temperature and molting on the respiration of Macropetasma africanus Balss (Decapoda: Penaeidea). Comp. Biochem. Physiol. 81A, 143-148.

Córdova Murueta, J.H., García-Carreño, F.L., Navarrete-del-Toro, M.L.A., 2004. Effect of stressors on shrimp digestive enzymes from assays of feces: an alternate method of evaluation. Aquaculture 233, 439-449.

Costa, A.M., Buglione, C.C., Bezerra, F.L., Martins, P.C.C., Barracco, M.A., 2009. Immune assessment of farm-reared Penaeus vannamei shrimp naturally infected by IMNV in NE Brazil. Aquaculture 291, 141-146.

Drach, P., 1939. Mue et cycle d'intermue chez les crustacés décapodes. Annales de l'Institut Océanographique de Paris N.S. 19, 103-391.

Erlanger, S., Kokowsky, N., Cohen, W., 1961. The preparation and properties of two chromogenic substrates of trypsin. Arch. Biochem. Biophys. 95: 27-278.

Fegan, D. F., and Clifford III, H. C., 2001. Health management for viral diseases in shrimp farms. In: Browdy, C.L., Jory, D.E. (Ed.), "Special Session on Sustainable Shrimp Culture, Aquaculture 2001”, pp. 168-198. The World Aquaculture Society, Baton Rouge, Louisiana, USA.

Gauquelin, F., Cuzon, G., Gaxiola, G., Rosas, C., Arena, L., Bureau, D.P., Cochard, J.-C., 2007. Effect of dietary protein level on growth and energy utilization by Litopenaeus stylirostris under laboratory conditions. Aquaculture 271, 439-448.

Goarant, C., Boglio, E., 2000. Changes in hemocyte counts in Litopenaeus stylirostris subjected to sublethal infection and to vaccination. J. World Aquac. Soc. 31, 123-129.

Goarant, C., Ansquer, D., Herlin, J., Domalain, D. , Imbert, F., de Decker S, 2006a. Summer Syndrome in Litopenaeus stylirostris in New Caledonia: Pathology and epidemiology of the etiological agent, Vibrio nigripulchritudo. Aquaculture 253, 105-113.

Goarant, C., Herlin, J., Ansquer, D., Brizard, R., Marteau A.L., 2004b. Vibrio penaeicida et le Syndrome 93 dans les fermes de crevettes de Nouvelle-Calédonie: revue et perspectives. In : Styli 2003. Trente ans de crevetticulture en Nouvelle-Calédonie. Nouméa-Koné, 2-6 June 2003. Ed. Ifremer, Actes Colloq. 38, p. 203-209

Goarant, C., Lemonnier, H., Mugnier, C., Herbland, A., 2004a. Synthèse provisoire sur l'approche pluridisciplinaire du syndrome d'été. (Programme DeSanS). In : Styli 2003. Trente ans de crevetticulture en Nouvelle-Calédonie. Nouméa-Koné, 2-6 June 2003. Ed. Ifremer, Actes Colloq. 38, p. 255-260

Goarant, C., Reynaud, Y., Ansquer, D., de Decker, S., Merien, F, 2007. Sequence polymorphism-based identification and quantification of Vibrio nigripulchritudo at the species and subspecies level targeting an emerging pathogen for cultured shrimp in New Caledonia. J. Microbiol. Methods 70, 30-38.

Goarant, C., Reynaud, Y., Ansquer, D., de Decker, S., Saulnier, D., Le Roux, F., 2006b. Molecular epidemiology of Vibrio nigripulchritudo, a pathogen of cultured penaeid shrimp (Litopenaeus stylirostris) in New Caledonia. Syst. Appl. Microbiol. 29, 570-580.

Hagerman, L., Søndergaard, T., Weile, K., Hosie, D., Uglow, R.F., 1990. Aspects of blood physiology and ammonia excretion in Nephrops norvegicus under hypoxia. Comp. Biochem. Physiol. 97A, 51-55. 
Hall, M.R., VanHam, E.H., 1998. The effects of different types of stress on blood glucose in the giant tiger prawn Penaeus monodon. J. World Aquac. Soc. 29, 290- 299.

Hennig, O., Itami, T., Maeda, M., Kondo, M., Natsukari, Y., Takahashi, Y., 1998. Analyses of hemolymph immunoparameters in kuruma shrimp infected with Penaeid rod-shaped DNA virus. Fish Path. 33, 389-393.

Hsieh, S.-L., Ruan, Y.-H., Li, Y.-C., Hsieh, P.-S., Hu, C.-H., Kuo, C.-M., 2008. Immune and physiological responses in Pacific white shrimp (Penaeus vannamei) to Vibrio alginolyticus. Aquaculture 275, 335-341.

Johansson, M.W., Keyser, P., Sritunyalucksana, K., Söderhäll, K., 2000. Crustacean hemocytes and haematopoiesis. Aquaculture 191, 45-52.

Jussila, J., McBride, S., Jago, J., Evans, L.H., 2001. Hemolymph clotting time as an indicator of stress in western rock lobster (Panulirus cygnus George). Aquaculture 199, 185-193.

Lemonnier, H., Bernard, E., Boglio, E., Goarant, C., Cochard, J.-C., 2004. Influence of sediment characteristics on shrimp physiology: $\mathrm{pH}$ as principal effect. Aquaculture 240, 297-312.

Lemonnier, H., Courties, C., Mugnier, C., Torréton, J.-P., Herbland, A., 2010. Nutrient and microbial dynamics in eutrophying shrimp ponds affected or unaffected by vibriosis. Mar. Pollut. Bull. 60, 402-411.

Lemonnier, H., Herbland, A., Salery, L., Soulard, B., 2006. "Summer syndrome" in Litopenaeus stylirostris grow out ponds in New Caledonia: zootechnical and environmental factors. Aquaculture 261, 1039-1047.

Le Moullac, G., Haffner, P., 2000. Environmental factors affecting immune responses in Crustacea. Aquaculture 191, 121-131.

Le Moullac, G., Le Groumellec, M., Ansquer, D., Froissard, S., Lecy, P., Aquacop, 1997. Haematological and phenoloxidase activity changes in the shrimp Penaeus stylirostris in relation with the moult cycle: protection against vibriosis. Fish Shellfish Immunol. 7, 227-234.

Le Moullac, G., Soyez, C., Saulnier, D., Ansquer, D., Avarre, J.-C., Levy, P., 1998. Effect of hypoxic stress on the immune response and the resistance to vibriosis of the shrimp Penaeus stylirostris. Fish Shellfish Immunol. 8, 621-629.

Lightner, D.V., 1988. Vibrio disease of Penaeid shrimp. In: Sindermann, C.J., Lightner, D.V. (Eds), Disease diagnosis and control in north American marine aquaculture", Vol. 17, pp. 42-47, Elsevier, Miami, Florida, USA.

Lightner, D.V., Redman, R.M., 1998. Shrimp diseases and current diagnostic methods. Aquaculture 164, 201-220.

Lignot, J.H., Cochard, J.-C., Soyez, C., Lemaire, P., Charmantier, G., 1999. Osmoregulatory capacity according to nutritional status, molt stage and body weight in Penaeus stylirostris. Aquaculture 170, 79-92.

Lignot, J.H., Spanings-Pierrot, C., Charmantier, G., 2000. Osmoregulatory capacity as a tool in monitoring the physiological condition and the effect of stress in crustaceans. Aquaculture 191, 209-245.

Liu, C.-H., Yeh, S.-T., Cheng, S.-Y., Chen, J.-C., 2004. The immune response of the white shrimp Litopenaeus vannamei and its susceptibility to Vibrio infection in relation with the moult cycle. Fish Shellfish Immunol. 16, 151-161. 
Lowry, O.H., Rosebrough, N.J., Lewis Farr, A., Randall, R.J. 1951. Protein measurement with the folin phenol reagent. J. Biol. Chem. 193: 265-275.

Mermoud, I., Costa, R., Ferré, O., Goarant, C., Haffner, P., 1998. "Syndrome 93" in New Caledonian outdoor rearing ponds of Penaeus stylirostris: history and description of three major outbreaks. Aquaculture 164, 323-335.

Morritt, D., Spicer, J.I., 1993. A brief re-examination of the function and regulation of extracellular magnesium and its relationship to activity in crustacean arthropods. Comp. Biochem. Physiol. 106A, 19-23.

Mugnier, C., Justou, C., 2004. Combined effect of external ammonia and molt stage on the blue shrimp Litopenaeus stylirostris physiological response. J. Exp. Mar. Biol. Ecol. 309, 35-46.

Mugnier, C., Lemonnier, H., Legrand, A., 2006. Physiological response of the blue shrimp Litopenaeus stylirostris to short-term confinement on a pond bottom. Aquaculture 253, 703-711.

Mugnier, C., Soyez, C., 2005. Response of the blue shrimp Litopenaeus stylirostris to temperature decrease and hypoxia in relation to molt stage. Aquaculture 244, 315-322.

Mugnier, C., Zipper, E., Goarant, C., Lemonnier, H., 2008. Effect of exposure to ammonia and hypoxia on the blue shrimp Litopenaeus stylirostris survival and physiological response in relation to molt stage. Aquaculture 274, 398-407.

Paul, R.J., Pirow, R., 1997/98. The physiological significance of respiratory proteins in invertebrates. Zoology 100, 298- 306.

Racotta, I.S., Hernandez-Herrera, R., 2000. Metabolic responses of the white shrimp, Penaeus vannamei, to ambient ammonia. Comp. Biochem. Physiol. 125A, 437-443.

Rolland, J.L., Abdelouahab, M., Dupont, J., Lefevre, F., Bachère, E., Romestand, B. 2010. Stylicins, a new family of antimicrobial peptides from the Pacific blue shrimp Litopenaeus stylirostris. Mol. Immunol. 47, 1269-1277;

Sánchez-Paz, A., Garcia-Carreño, F.G., Hernández-López, J., Muhlia-Almazán, A., YepizPlascencia, G., 2007. Effect of short-term starvation on hepatopancreas and plasma energy reserves of the Pacific white shrimp (Litopenaeus vannamei). J. Exp. Mar. Biol. Ecol. 340, 184-193.

Sainz Hernández, J.C., Córdova Murueta, J.H., 2009. Activity of trypsin from Litopenaeus vannamei. Aquaculture 290, 190-195.

Smolders, R., Baillieul, M., Blust, R., 2005. Relationship between the energy status of Daphnia magna and its sensitivity to environmental stress. Aquat. Toxic. 73, 155-170.

Sniezsko, S.F., 1974. The effects of environmental stress on outbreaks of infectious diseases of fish. J. Fish Biol. 6, 197-208.

Song, Y.-L., Yu, C.-I., Lien, T.-W., Huang, C.-C., Lin, M.-N., 2003. Hemolymph parameters of Pacific white shrimp (Litopenaeus vannamei) infected with Taura syndrome virus. Fish Shellfish Immunol. 14, 317-331.

Wabete, N., Chim, L., Lemaire, P., Massabuau, J.-C., 2008. Life on the edge: physiological problems in penaeid prawns Litopenaeus stylirostris, living on the low side of their thermopreferendum. Mar. Biol. 154, 403-412. 
1 Walling, E., Vourey, E., Ansquer, D., Beliaeff, B., Goarant, C., 2010. Vibrio nigripulchritudo 2 monitoring and strain dynamics in shrimp pond sediments. J. Appl. Microbiol. 108, 3 2003-2011.

4 Yoganandhan, K., Thirupathi, S., Sahul Hameed, A.S., 2003. Biochemical, physiological and 5 hematological changes in white spot syndrome virus-infected shrimp, Penaeus indicus. 6 Aquaculture 221, 1-11.

7 
1 Table 1: Mean percentage of each molt stage observed during the period d32-80 in the

2 sampled populations of control farm (farm HC) and farm affected by the "summer syndrome"

3 (farm DF).

Molt stages

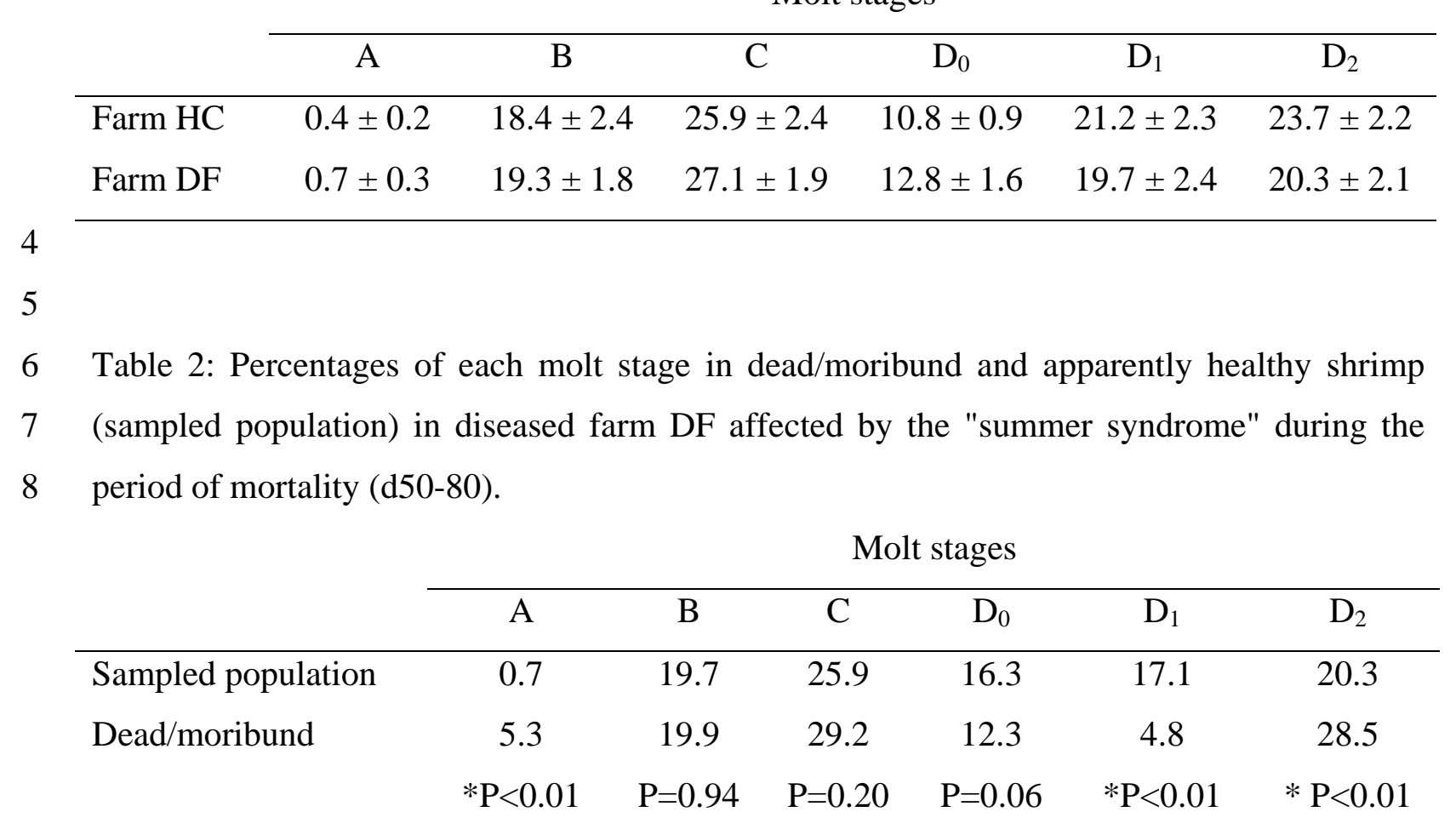

*Significant differences between population and dead/moribund shrimp for each molt stage (ANOVA)

Table 3: Physical/health conditions: Percentages of shrimp which presented rostrum or exoskeleton deformity, an empty gut, necrotic lesions on the external body surface, orangecoloured gills, red-coloured appendage segments and opaqueness of abdominal muscle in the sampled population of control farm (farm HC) and farm affected by the summer syndrome (farm DF).

\begin{tabular}{ccccccc}
\hline & Deformity & $\begin{array}{c}\text { Empty } \\
\text { gut }\end{array}$ & $\begin{array}{c}\text { Necrotic } \\
\text { lesions }\end{array}$ & $\begin{array}{c}\text { Coloured } \\
\text { gills }\end{array}$ & $\begin{array}{c}\text { Red } \\
\text { segments }\end{array}$ & $\begin{array}{c}\text { Opaqueness of } \\
\text { abdominal muscle }\end{array}$ \\
\hline Farm HC & 0.5 & 13.7 & 1.7 & 1.1 & 5.4 & 19.8 \\
Farm DF & 0.3 & 9.1 & 0.4 & 3.1 & 2.5 & 9.0 \\
& $p=0.28$ & ${ }^{*} p<0.01$ & $* p<0.01$ & $p=0.07$ & ${ }^{*} p<0.01$ & ${ }^{*} p<0.01$
\end{tabular}


1 Table 4: Statistical results (p values) of ANCOVA with farm and molt stage as factors and 2 weight as cofactor in shrimp free of pathogen, farm DF.

\begin{tabular}{llrrr} 
& Parameter & Farm & Molt stage & Weight \\
\hline Hemolymph & Glucose & $<0.01$ & $<0.01$ & $<0.01$ \\
& Oxyhaemocyanin & 0.03 & $<0.01$ & $<0.01$ \\
& Mg ions & $<0.01$ & $<0.01$ & 0.13 \\
& Total proteins & 0.04 & $<0.01$ & $<0.01$ \\
& Osmotic pressure & 0.06 & $<0.01$ & $<0.01$ \\
& Lactate & $<0.01$ & $<0.01$ & $<0.01$ \\
& THC & $<0.01$ & $<0.01$ & $<0.01$ \\
\hline Hepatopancreas & Hepatosomatic index & $<0.01$ & 0.70 & $<0.01$ \\
& Total proteins & $<0.01$ & 0.66 & $<0.01$ \\
& Glucose & 0.16 & 0.81 & $<0.01$ \\
& Trypsine activity & $<0.01$ & 0.22 & 0.79 \\
\hline
\end{tabular}

3

4

5

6 Table 5: Comparison between VN+ and Vn- shrimp in DF. Statistical results (p values) of 7 ANCOVA with Vibrio nigripulchritudo and molt stage as factors and weight as cofactor.

\begin{tabular}{llrrr} 
& Parameter & V nigri & Molt stage & Weight \\
\hline Hemolymph & Glucose & $<0.01$ & $<0.01$ & $<0.01$ \\
& Oxyhaemocyanin & $<0.01$ & $<0.01$ & $<0.01$ \\
& Mg ions & $<0.01$ & $<0.01$ & $<0.01$ \\
& Total proteins & $<0.01$ & $<0.01$ & $<0.01$ \\
& Osmotic pressure & $<0.01$ & $<0.01$ & 0.33 \\
& Lactate & $<0.01$ & $<0.01$ & $<0.01$ \\
& THC & 0.01 & 0.03 & 0.46 \\
\hline \multirow{2}{*}{ Hepatopancreas } & Hepatosomatic index & 0.87 & 0.46 & $<0.01$ \\
& Total proteins & 0.10 & 0.86 & $<0.01$ \\
& Glucose & 0.97 & 0.37 & 0.28 \\
& Trypsine activity & 0.87 & 0.10 & $<0.01$ \\
\hline
\end{tabular}



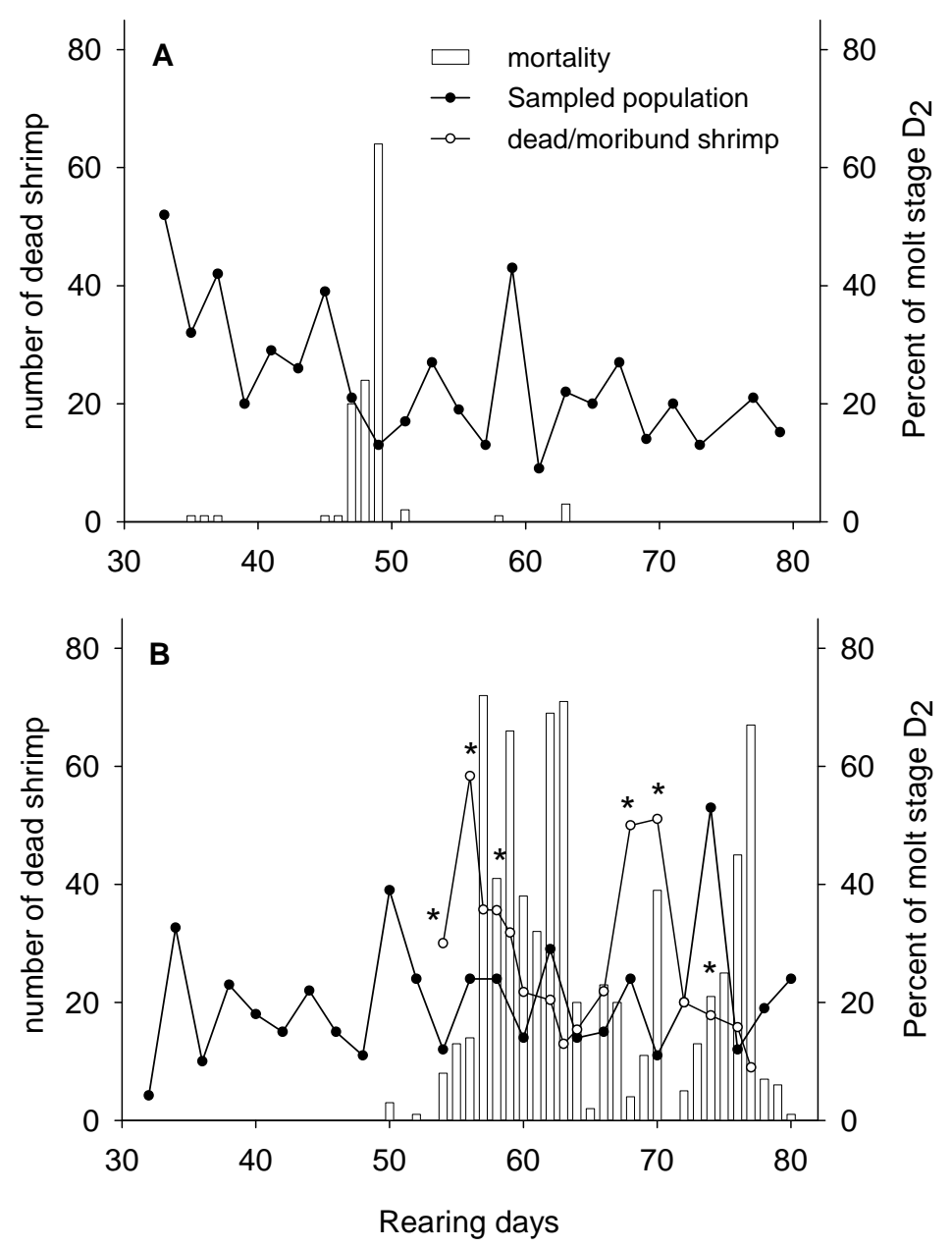

1

2 Figure 1: Daily number of dead shrimp observed and percentages of apparently healthy and 3 dead/moribund shrimp in late premolt stage $\mathrm{D}_{2}$ in (A) farm HC and (B) farm DF.

4 *indicates significant difference between apparently healthy and dead/moribund shrimp in 5 stage $\mathrm{D}_{2}(<$ chi $>2, p<0.05)$ 


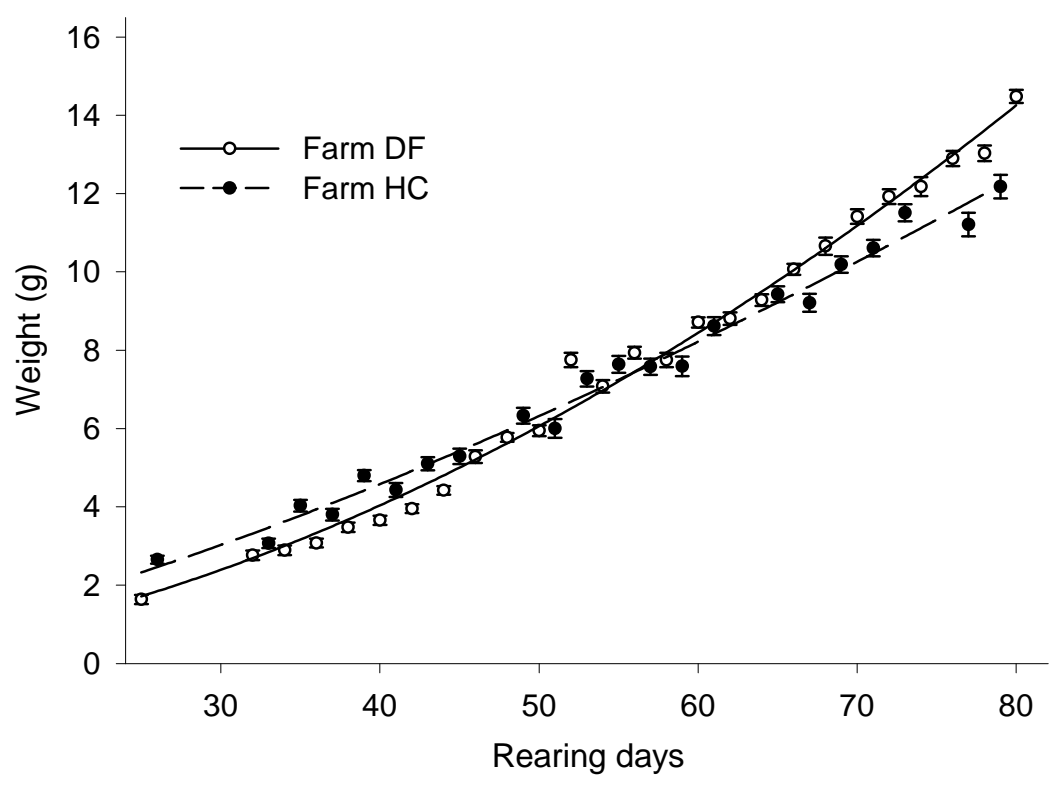

2

3 Figure 2: Daily average ( \pm S.E.) weight for farm HC (black circles) and farm affected by 4 Summer Syndrome (farm DF, open circles).

5 

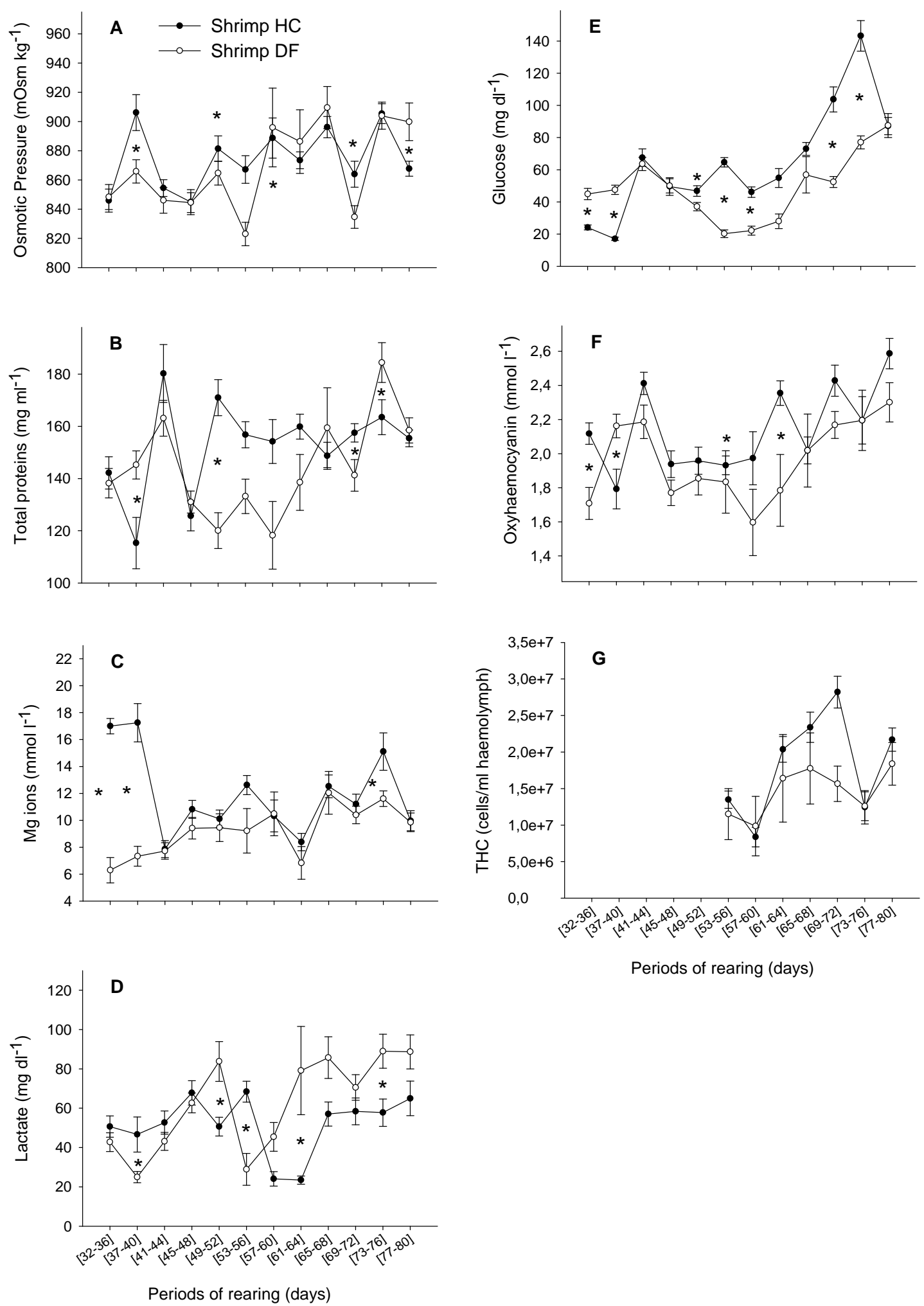

Periods of rearing (days)

1 Figure 3: Osmotic pressure (A), Total proteins concentration (B), Mg ions concentration (C),

2 Lactate concentration (D), Glucose concentration (E), oxyhaemocyanin concentration (F) and

3 Total hemocyte count (G) in the hemolymph of pathogen-free (Vn-) shrimps in stage $\mathrm{C}$ and

4 D2 from a control farm (Farm HC) and a farm affected by Summer Syndrome (Farm DF)

5 between $\mathrm{d} 32$ and d80 of the rearing. Mean \pm SE. $n=11-59$ for farm HC and 5-58 for farm

6 DF. * indicates significant differences between farms (ANOVA, $p<0.05$ ). 

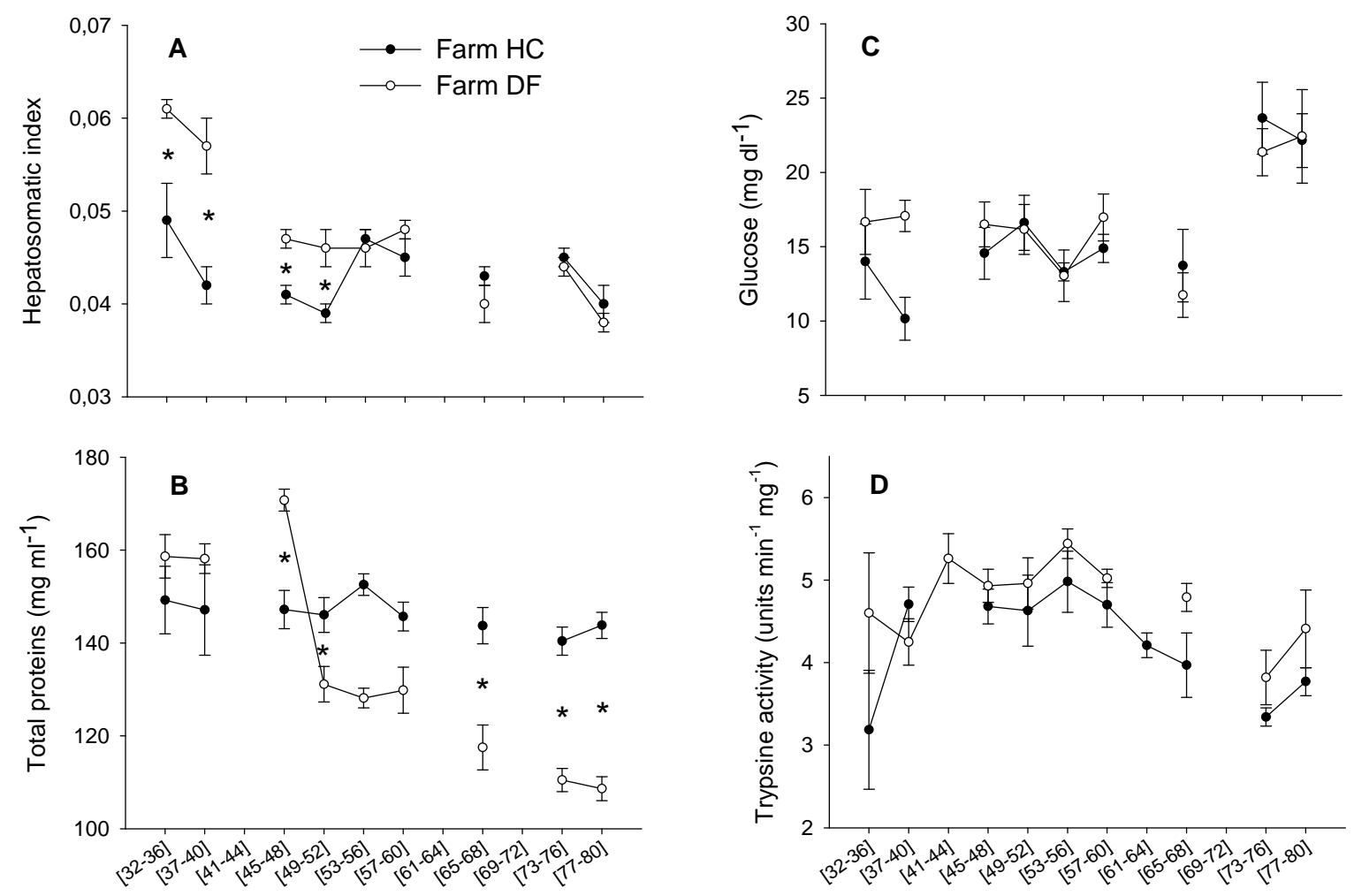

2 Figure 4: Hepatosomatic index (A), Total protein concentration (B), Glucose concentration

3 (C), trypsine activity in the hepatopancreas of shrimps in stage $\mathrm{C}$ from a control farm (Farm

4 HC) and a farm affected by Summer Syndrome (Farm DF) between d32 and d80 of rearing. 5 

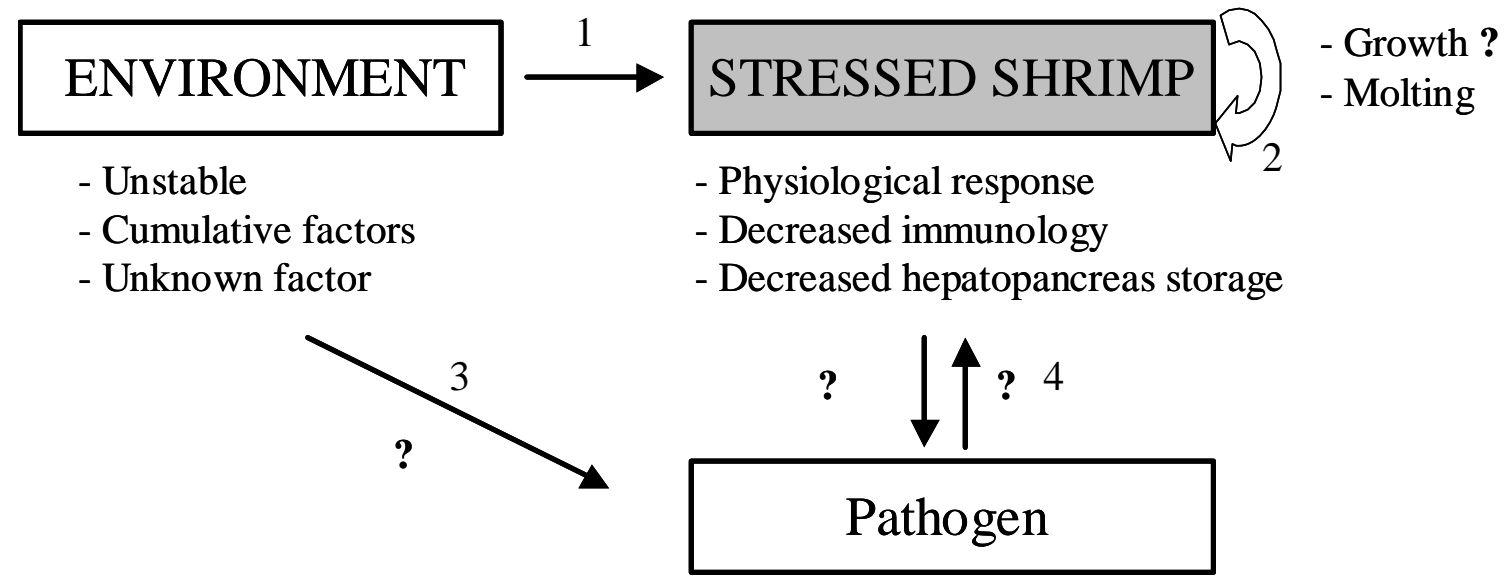

-Increasing concentration

-Virulence

3 Figure 5: Schematic representation of the "disease model” conceptualized from the literature

4 (Sniezsko, 1974; Lightner and Redman, 1998) and from data previously published by

5 Goarant et al. (2006a), Lemonnier et al. (2010) and presented in this manuscript.

6 